\title{
Estudo das atividades de trabalho remuneradas desenvolvidas por detentos: o caso da penitenciária estadual de Maringá
}

\author{
A Study of paid labor activities developed by jailed people: the case of state \\ prison of Maringá
}

\author{
Maria Iolanda Sachuk ${ }^{*}$ \\ Alfredo Lopes da Costa Moreira Neto ${ }^{* *}$
}

\begin{abstract}
Resumo
A questão carcerária sempre fez parte da pauta de discussão nos mais diversos segmentos da sociedade. No Brasil, uma das conseqüências mais graves desse problema é o alto índice de criminalidade observado diariamente. $O$ presente artigo tem por objetivo identificar as atividades de trabalho remuneradas desenvolvidas pelos detentos na Penitenciária Estadual de Maringá - PEM e revelar se, na concepção dos presos e da direção da PEM, estas atividades coadunam com os objetivos prescritos no artigo 28 da Lei de Execução Penal, Lei no. 7210 , de 11 de julho de 1984. Os dados mostram que a PEM está em sintonia com o que a sociedade idealizou para esse tipo de instituição na atualidade: ao mesmo tempo em que existe o exercício do controle e da dominação, há também um discurso que tem como proposta a possibilidade de ressocialização do preso.
\end{abstract}

Palavras-chave: Instituições Totais; Lei de Execução Penal; Presídios. Trabalho.

\begin{abstract}
Prison issues are always on the discussion list among the various sections of society. One of the problem's most serious consequences in Brazil is the daily high crime rates. Current essay identifies paid labor activities undertaken by jailed peoples in the State Prison of Maringá (SPM) and discusses whether jailed people and the SPM administration admit that such activities meet the aims prescribed by Article 28 of Penal Law, Law 7210 of the 11th July 1984. Data show that SPM is fine-tuned to what the community imagined for such current institutions. Control and domination coexist with a discourse on the possibility of the re-socialization of jailed people.
\end{abstract}

Key words: Total Institutions; Penal Law; Prisons. Labor.

\footnotetext{
* Professora doutora, Departamento de Administração da UEM E-mail: misachuk@uem.br.

** Vice-Diretor da Penitenciária Estadual de Maringá, mestre em Administração PPA/UEM/UEL E-mail: alcmneto@pr.gov.pr.
} 


\section{Introdução}

O sistema prisional brasileiro tem sido foco de atenções nos últimos anos e os estudos em relação às várias áreas que o abrangem têm sido intensificados pela importância que é uma instituição prisional no contexto social em que está inserida. 0 que regulamenta o funcionamento de toda essa estrutura é a Lei de Execução Penal (BRASIL, 1984).

A LEP - Lei de Execução Penal determina como deve ser executada e cumprida a pena de privação de liberdade e restrição de direitos, privilegiando, além do pagamento da dívida social do apenado, a idéia da reabilitação, o que, sem dúvida, demanda uma estrutura composta por pessoas e outros recursos que nem sempre correspondem às expectativas e exigências de tão complexa missão.

Não é segredo que o sistema prisional, de forma geral, apresenta estrutura arcaica e pessoal nem sempre bem preparado para atuar vislumbrando algo além da custódia, resultando no que se vê constantemente na mídia: o caos do sistema evidenciado sob a forma de rebeliões, mortes e depredação. Dessa forma, esses e outros problemas ocorrem pelas (nem sempre ideais) condições de funcionamento da maioria das prisões e também em função da carência de escolas penitenciárias para a formação de pessoal com competência para exercer a função, acima de tudo, de educador junto aos encarcerados.

De acordo com informações do Departamento Penitenciário Nacional, em dezembro de 2004 havia cerca de trezentas e trinta e seis mil pessoas presas no país (PARANÁ, 2005). Segundo Silva (2001), o principal segmento das prisões é constituído por pessoas provindas das camadas mais pobres da sociedade, cujos sujeitos geralmente apresentam baixa escolaridade, célula familiar desestruturada, desqualificação profissional, participação precária no mercado de trabalho, dentre outras características. Isso faz com que, mesmo depois de pagar à sociedade pelos erros cometidos, muitos deles tenham dificuldades para se reinserir novamente nela, após o cumprimento de suas penas.

Com isso, a utilização do trabalho remunerado, não como forma de punição, e sim de recuperação do preso, tem sido muito discutida e gradativamente implementada em diversos presídios, como é o caso da Penitenciária Estadual de Maringá - PEM. 
Diferentes formas, no Brasil, de utilização de mão-de-obra carcerária podem advir de quem cumpre pena em regime fechado, tanto a partir de trabalho a ser realizado dentro das unidades penais, como fora - no caso da realização de obras públicas; e em regime semi-aberto, nas penitenciárias industriais, penitenciárias agrícolas e trabalhos externos para empresas privadas e outras entidades.

Na PEM isso ocorre na primeira situação, ou seja, para quem cumpre pena em regime fechado. Na atual concepção da LEP, faz parte das diretrizes gerais a questão do trabalho para o preso não como punição, mas sim como processo de reeducação, geração de renda e produção. Além disso, a cada três dias trabalhados o preso obtém a remissão de um dia de pena, o que pode ser visto nos artigos da LEP n.o 7.210, de 11/07/1984 (BRASIL, 1984) transcritos abaixo:

Art. 28. O trabalho do condenado, como dever social e condição de dignidade humana, terá finalidade educativa e produtiva. Art. 29. O trabalho do preso será remunerado, mediante prévia tabela, não podendo ser inferior a $3 / 4$ (três quartos) do salário mínimo [...]. Art. 126. O condenado que cumpre a pena em regime fechado ou semi-aberto poderá remir, pelo trabalho, parte do tempo de execução da pena. §1으 A contagem do tempo, para o fim deste artigo, será feita à razão de 1 (um) dia de pena por 3 (três) de trabalho.

Sendo assim, sem que se desvirtue o propósito punitivo da condenação criminal, o que a legislação atual busca é a viabilização de um processo de socialização do apenado, dando-Ihe a perspectiva de formação profissional para que, no futuro, quando do retorno à sociedade, o mesmo possa trabalhar em empresas ou criar seu próprio negócio. Com base nesse contexto, buscou-se, a partir da realização de uma pesquisa, responder à seguinte indagação: na concepção dos detentos e da direção da PEM, as atividades de trabalho remuneradas desenvolvidas por presos coadunam com os objetivos prescritos no art. 28 da Lei 7.210, de 11/07/1984?

Para tanto, o artigo está dividido em cinco partes: a primeira, composta por esta introdução, seguida por uma breve discussão teórica sobre organizações, instituições totais e presídios. Em seguida, são apresentados os procedimentos metodológicos utilizados para a realização da pesquisa de campo que deu origem a este artigo. Os dados coletados são apresentados e, por fim, são expostas as conclusões do trabalho. 


\section{Definindo Organizações}

Não se pode ignorar o fato de que as organizações existem, mas a razão de estarem presentes no mundo atual de forma cada vez mais atuante e inseridas no contexto social aponta para a necessidade de estudá-las tanto em termos de sua dinâmica de funcionamento como também na questão do relacionamento com a sociedade. Quando se questiona sobre a razão de se compreender e estudar as organizações, as respostas que se apresentam são cada vez mais evidentes, pois as organizações acabam por envolver o homem, de forma dominadora, em todo o curso de sua existência.

Para Hall (2004), é intensa a presença das organizações na vida do homem e é impossível evitá-las, tal qual a morte ou o pagamento de impostos. Estudar as organizações, portanto, não se trata de um simples exercício acadêmico, já que, estejam elas em que nível for, sempre serão peças importantes nos processos de mudanças sociais, a exemplo do que vem ocorrendo ao longo da história.

As indagações sobre o porquê da existência das organizações têm orbitado sobre a afirmação de que na realização de tarefas, geralmente, o esforço coletivo alcança resultados melhores que o individual. Quanto ao entendimento sobre as organizações, as definições servem para que se tenha uma base referencial, em busca da compreensão daquilo que se pretende estudar. Pois, a esse respeito, as organizações, já há longo período, têm sido avaliadas e discutidas por autores clássicos como Max Weber, Chester Barnard, dentre outros.

Sobre Weber e Barnard, Hall (2004) faz uma síntese sobre suas respectivas reflexões a respeito de organizações. O autor inicia com Weber, que se destaca pelas suas considerações sobre burocracia e autoridade, além de seu reconhecido empenho na definição de organização. Hall (2004), então, mostra que Weber, ao apresentar sua concepção sobre organização, enfatiza o que denominou de grupo corporativo, a fim de demonstrar uma relação social fechada, cujo acesso de novos ingressantes está vinculado a uma complexa relação de hierarquia, autoridade e vontade dos membros (chefes/superiores) em suas funções usuais e específicas, inerentes aos objetivos do trabalho. 
Além disso, as organizações possuem pessoas interagindo, desenvolvendo relações sociais, e a idéia de grupo corporativo é ratificada quando fica claro que sua relação inclui alguns segmentos da população e exclui outros. A visão de Weber, além do grupo corporativo, abrange também o fato de que nas organizações nada acontece por acaso, e que as interações ocorrem por meio de associações formais, ao invés de associações comunitárias como normalmente acontece na sociedade. Portanto, padrões de interação ocorrem entre os membros das organizações de forma legítima, em busca do alcance de objetivos estabelecidos. Sua idéia de que as organizações são criadas para cumprir uma finalidade, fazer algo, é ainda hoje considerada pelos estudiosos e analistas da área (HALL, 2004).

Já Barnard, mesmo apresentando pontos em comum com o pensamento de Weber, desenha uma perspectiva diferente em que o papel do indivíduo é evidenciado, partindo das articulações entre duas ou mais pessoas em busca de um propósito comum. Sua concepção sobre organização parte do pressuposto de que os indivíduos que a compõem (membros do sistema) é que devem ser focados, pois são os responsáveis em comunicarse entre si e tomar decisões, enquanto Weber privilegia o sistema (HALL, 2004).

Seguindo com as definições sobre organizações, Srour (1998, p. 108) diz serem as organizações "agentes coletivos, à semelhança das classes sociais, das categorias sociais e dos públicos [...], são planejadas de forma deliberada para realizar um determinado objetivo". Nessa perspectiva, o autor referencia ainda como principais organizações formais as públicas, as privadas e as sem fins lucrativos, salientando o fato de que cada uma delas apresenta características muito peculiares que as diferenciam, inclusive daquelas que pertencem à mesma categoria. No entanto, trazem em seu escopo, objetivos bem definidos e um papel importante na sociedade atual.

Vale apresentar aqui a perspectiva de Hall (2004, p. 30), quando afirma que:

Uma organização é uma coletividade com uma fronteira relativamente identificável, uma ordem normativa (regras), níveis de autoridade (hierarquia), sistemas de comunicação e sistemas de coordenação dos membros (procedimentos); essa coletividade existe em uma base relativamente contínua, está inserida em um ambiente e toma parte de atividades que normalmente se encontram relacionadas a um conjunto de metas; as atividades acarretam conseqüências para os membros da organização, para a própria organização e para a sociedade. 
As organizações são entes concretos (indústrias, bancos, lojas de varejo, escritórios de serviço, etc.) e não podem ser confundidas com instituições, que se caracterizam com um fenômeno social, constituído por pessoas que possuem comportamentos, valores, crenças comuns e, geralmente, se relacionam baseados em normas e procedimentos estabelecidos.

Blau e Scott (1977, p. 16) abordam essa questão mencionando:

[...] relações sociais entre indivíduos e grupos e a estrutura de posição definida por eles constituem o centro da organização social de uma coletividade, mas não o seu todo. A outra principal dimensão da organização social é um sistema de crenças e orientações compartilhadas que servem como standards para a conduta humana.

O que se pode observar na atualidade é que o mundo é formado por organizações e que o homem contemporâneo faz parte dessas organizações que estão incumbidas de realizar grandes projetos. E trabalhar em grandes projetos, demanda o envolvimento de milhares de pessoas.

É certo que não se pode desvincular organizações de pessoas, pois são elas que constituem tais organizações, pois um amontoado de equipamentos, materiais e utensílios, com certeza, não teria muita importância se não servisse de suporte aos homens que delas fazem parte.

Dentro dessas estruturas, o homem figura como o centro das atenções e, por conseguinte, é responsável pelas questões de maior importância na complexa missão de gerir as organizações, ficando aquelas relativas a condições materiais relegadas a um plano acessório. É bom não esquecer, todavia, que as condições materiais também são importantes para o entendimento da dinâmica de funcionamento das organizações e algumas vezes o homem é colocado em segundo plano por causa delas. Por exemplo, na concepção de Perrow (1972), nas organizações modernas as pessoas são freqüentemente vistas como a fonte dos problemas, geralmente oriundos do exercício do trabalho e do relacionamento entre elas.

A vida organizacional, sob o enfoque sociológico, pode ser abordada a partir das organizações formais, que possuem as mais variadas características, ou seja: porte, número de pessoas envolvidas, ramo de atividade, enfim, uma série de aspectos que acaba por caracterizá-las e Ihes dar identidade própria. É bem verdade que, ao tratarmos 
as organizações formais, também conhecidas como "complexas", não se pode perder de vista que dentro delas existe um emaranhado de relações informais que acabam por se incorporar ao todo da organização. A diferenciação de tais relações é apenas analítica, não havendo possibilidade de segmentá-las, pois a organização é uma só. Sobre essa questão, Blau e Scott (1977, p. 19), afirmam que:

[...] é impossível compreender a natureza de uma organização formal sem investigar as redes de relações informais e as normas extra-oficiais, assim como a hierarquia formal de autoridade e as regras oficiais, pois os padrões formalmente instituídos e aqueles que aparecem informalmente se entrelaçam inextricavelmente.

Então, a Penitenciária Estadual de Maringá, local de desenvolvimento da pesquisa efetivada, encontra-se inserida no rol das organizações complexas, sendo que suas características mais determinantes estão definidas no próximo item, que trata das instituições totais, em que se enquadram os presídios.

\section{Instituições Totais}

Instituições totais, diferente do que pode parecer, ainda existem na sociedade atual, embora talvez não como antes, cujo exemplo máximo de alijamento foram os campos de concentração. Mas suas estruturas hoje continuam grandes e aparentes, como é o caso do sistema penitenciário, dos hospitais psiquiátricos, das instituições religiosas que exigem clausura de seus adeptos, dos colégios internos e outros. Essas instituições se diferenciam em termos de maior abertura ou fechamento em relação à sociedade, mas de forma geral, elas não permitem muita abertura com o meio.

Portanto, um paralelo a se fazer consiste na avaliação do grau de fechamento das instituições e afirmar que todas apresentam uma tendência natural ao fechamento, observando que as estratégias de internação de indivíduos, em nossa sociedade, continuam como prática constante. Faz-se mister ressaltar que a relação social dos indivíduos pertencentes a essas instituições com o mundo externo percorre um caminho que acaba por apontar que, quanto mais fechadas, maiores são os níveis de restrição. 
A esse respeito, Goffman (1974) define instituição total como um ambiente de residência e trabalho, onde existe uma concentração de indivíduos, em condições semelhantes, alijados do convívio com a sociedade por expressivo período de tempo, o que acaba por configurar uma vida fechada e formalmente controlada. O autor afirma ainda que essas instituições acabam por sediar as atividades de trabalho, lazer, dentre outras que podem ser terapêuticas, correcionais, educativas, pedagógicas e profissionalizantes.

Percebe-se que a lógica de funcionamento das instituições totais inibe ou até mesmo extingue a autonomia, a responsabilidade, o espírito crítico dos indivíduos, com o intuito de torná-los inertes, obedientes e submissos. São "estufas" para mudar as pessoas (GOFFMAN, 1974).

Para Perrow (1972), os tipos de organização/instituição podem ser identificados por meio de critérios que as diferenciam a partir de suas funções atribuídas pela sociedade ou também pela maneira pela qual elas são controladas. A busca das instituições totais, quando inibem o contato entre o internado e o ambiente externo, é extraí-lo totalmente do mundo de onde se origina, a fim de que o processo de aprendizagem ao qual será submetido seja mais facilmente absorvido, isento de comparações, e mais suscetível às normas internas que lhes serão impostas.

Tais instituições totais podem ser vislumbradas em cinco situações distintas, de acordo com o que segue:

Em primeiro lugar, instituições criadas para cuidar das pessoas que, segundo se pensa, são incapazes e inofensivas; nesse caso estão as casas para cegos, velhos, órfãos e indigentes. Em segundo lugar, há locais estabelecidos para cuidar de pessoas consideradas incapazes de cuidar de si mesmas e que são também uma ameaça à comunidade, embora de maneira não intencional; sanatórios para tuberculosos, hospitais para doentes mentais e leprosários. Um terceiro tipo de instituição total é organizado para proteger a comunidade contra perigos intencionais, e o bem-estar das pessoas assim isoladas não constitui o problema imediato: cadeias, penitenciárias, campos de prisioneiros de guerra, campos de concentração. Em quarto lugar, há instituições estabelecidas com a intenção de realizar de modo mais adequado alguma tarefa de trabalho, e que se justificam apenas através de tais fundamentos instrumentais: quartéis, navios, escolas internas, campos de trabalho, colônias e grandes mansões (do ponto de vista dos que vivem nas moradias dos empregados). Finalmente, há os estabelecimentos destinados a servir de refúgio do mundo, embora muitas vezes sirvam também como locais de instrução para os religiosos; entre exemplos de tais instituições, é possível citar abadias, mosteiros, conventos e outros claustros (GOFFMAN, 1974, p. 16). 
Etzioni (1974) chama esse tipo de instituições como organizações coercitivas. É um posicionamento conveniente, que contribui sobremaneira para o entendimento da dinâmica das relações interpessoais e do funcionamento dessas instituições. Pois bem, nesse contexto, tais instituições totais, ou organizações coercitivas, são aquelas que se utilizam da coerção como meio de controle junto aos níveis inferiores, além de uma característica bastante marcante, que consiste no alto grau de alienação dos participantes dessas organizações.

O modelo de Etzioni (1974) pressupõe que nas organizações há formas de poder que induzem as pessoas a seguirem suas diretrizes; e também, há formas de participação, que fazem com que haja, por parte dos indivíduos, uma orientação avaliativo-receptiva em relação a um objeto. Nas organizações coercitivas, o poder utilizado é o coercitivo, que reside na aplicação ou ameaça de aplicação de sansões físicas, principalmente. E a participação existente é a alienativa, que segundo Etzioni $(1974$, p. 38) refere-se a "uma orientação intensamente negativa; é predominante nas relações entre estranhos hostis". Num continuum entre a alta e a baixa participação, ela está nesse último ponto, ou seja, o indivíduo não participa de nenhuma decisão; simplesmente, cumpre as ordens.

Assim, tomados em conjunto, os dois elementos - o poder aplicado pela organização aos participantes inferiores e a participação na organização desenvolvida por eles - constitui a relação de aceitação. Para Etzioni (1974), os internados são altamente alienados em relação às prisões, já que o poder coercitivo tende a alienar; para o autor, esse seria um tipo de consentimento congruente com esse tipo de organização.

Portanto, nessas instituições, o uso da força é fator importante como meio de consecução de seus objetivos principais. Nesse sentido, Etzioni (1974, p. 57) afirma que:

As organizações coercitivas são entidades nas quais a coerção é o principal meio de controle sobre os participantes dos níveis inferiores e a elevada alienação caracteriza a orientação da maioria deles em relação à instituição. Casos típicos são campos de concentração, campos de prisioneiros de guerra, a maioria das prisões, instituições correcionais tradicionais e hospitais de doenças mentais com internamento. Campos de trabalho forçado e centros de repatriamento são também organizações coercitivas. 
Vale salientar que os padrões coercitivos utilizados na manutenção do controle de tais instituições podem variar substancialmente, levando-se em conta as características e finalidades para as quais foram constituídas. Para Etzioni (1974), os campos de concentração empregam mais coerção do que as prisões regulares; as prisões utilizam mais do que as instituições correcionais para menores, sendo que, para Ohlin "este último tipo é, freqüentemente, o primeiro a introduzir reformas" (apud ETZIONI, 1974, p. 58). Para Etzioni (1974), uma forma de determinar empiricamente o lugar de uma organização no continuum coercitivo é estabelecer a punição típica para o mesmo tipo de ofensa em várias organizações. Por exemplo, a punição por tentativa de fuga de um campo de concentração foi freqüentemente morte ou tortura; de prisões, a extensão da sentença em um ano; em instituições correcionais, a duração da sentença era bem menor.

A realidade das instituições que fazem parte do sistema penal, nesse caso a Penitenciária Estadual de Maringá, merece aqui um parêntese a respeito dessa questão, pois possuem as características que as enquadram no rol das organizações coercitivas. Todavia, na atualidade, os padrões coercitivos não podem fugir significativamente dos parâmetros estabelecidos e normatizados para os tipos de punição que devem ser aplicados para determinados tipos de faltas, a não ser quando o assunto for tratado na informalidade. Para Etzioni (1974, p. 60), os hospitais para doentes mentais também possuem algumas características especiais:

\footnotetext{
Os hospitais para doenças mentais são difíceis de situar dessa forma, de vez que nessas organizações é dada uma interpretação diferente ao mesmo tipo de falta, e desde que outras formas de punição - algumas vistas como medidas terapêuticas - estão disponíveis, tais como choque elétrico, injeção de insulina e camisa de força. Na medida em que uma comparação pode ser feita, sugerimos que os hospitais de doenças mentais se assemelham as instituições correcionais para delinqüentes juvenis, mais do que a prisões, comparação que freqüentemente é feita. Parece que a juventude e a insanidade suavizam a orientação punitiva. Os indivíduos estão nos dois tipos de organização contra a sua vontade, mas a mesma falta pode trazer confinamento menos duradouro quando o faltoso é jovem ou legalmente definido como doente mental. Não existe pena capital em qualquer dessas organizações. Reabilitação e terapia, limitadas como possam ser, aparecem mais freqüentemente nesses dois tipos de organização do que em prisões. Ambas recaem na parte relativamente menos coerciva da categoria.
} 
Pode-se dizer que as organizações coercitivas hoje mais constantes e estudadas com maior freqüência são as prisões e os hospitais de doenças mentais, que representam uma amostra com informações para o entendimento das características e peculiaridades de tais instituições. Na maioria dos casos, o modus operandi dos presídios está em sintonia com o que as sociedades ao longo do tempo idealizaram para essas instituições, ou seja, o exercício do controle e da dominação, cujos efeitos são bastante adversos à proposta declarada de ressocialização.

Sobre essa questão, é oportuno o posicionamento de Goffman (1974) quando aborda o que denomina de ajustamentos secundários, como prerrogativa para que os internados sintam ainda certa autonomia sobre o ambiente em que vivem, atenuando sobremaneira as influências e as pressões que sofrem. Diz o autor que tais ajustamentos secundários são "[...] práticas que não desafiam diretamente a equipe dirigente, mas que permitem que os internados consigam satisfações proibidas ou obtenham, por meios proibidos, as satisfações permitidas" (GOFFMAN, 1974, p. 161).

Mais um aspecto que merece consideração é a já mencionada questão da impermeabilidade ou invisibilidade das instituições prisionais (e de outras instituições totais). Com isso, a sociedade se abstrai da dura realidade vivida pelos seus colaboradores e internados, levando a crer que tais instituições são ambientes impenetráveis e ilhados em relação à sociedade. O ideal seria que elas pudessem estar inseridas, mormente no que concerne ao estabelecimento de políticas públicas, em um contexto que privilegiasse uma proposta de reabilitação para a liberdade.

Um posicionamento interessante sobre o assunto é feito por Goffman (1974, p. 17), quando afirma que:

\footnotetext{
Uma disposição básica da sociedade moderna é que o indivíduo tende a dormir, brincar e trabalhar em diferentes lugares, com diferentes co-parcipantes, sob diferentes autoridades e sem um plano racional geral. $O$ aspecto central das instituições totais pode ser descrito com a ruptura das barreiras que comumente separam essas três esferas de vida. Em primeiro lugar, todos os aspectos da vida são realizados no mesmo local e sob uma única autoridade. Em segundo lugar, cada fase da atividade diária do participante é realizada na companhia imediata de um grupo relativamente grande de outras pessoas, todas elas tratadas da mesma forma e obrigadas a fazer as mesmas coisas em conjunto. Em terceiro lugar, todas as atividades diárias são rigorosamente estabelecidas em horários, pois uma atividade leva, em tempo predeterminado, à seguinte, e toda a seqüência de atividades é imposta de cima, por um sistema de regras formais explícitas e um grupo de funcionários. Finalmente, as várias
} 
atividades obrigatórias são reunidas num plano racional único, supostamente planejado para atender aos objetivos oficiais da instituição.

O que se deve considerar, a partir disso, é que as prisões, como um tipo de instituição total, por meio de princípios doutrinários, segregam seus ocupantes das influências do ambiente externo, em maior ou menor medida, e entendem que, com isso, irão facilitar o processo de ressocialização, utilizando suas estruturas hierárquicas (normativas, coercitivas, etc.) para potencializar os resultados das propostas de reeducação do internado.

\section{Os Presídios}

Dentro da classificação de instituições totais encontram-se os presídios, também denominados de instituições penais, penitenciárias, etc. Como dito anteriormente, tais instituições totais apresentam características bastante peculiares, variando, entretanto, quanto ao rigor de suas normas, geralmente vinculadas aos objetivos que perseguem e ao papel que desempenham na sociedade.

No caso dos presídios, geralmente existe um grupo numeroso de internados sendo supervisionado por equipe reduzida de técnicos administrativos e agentes penitenciários, que perseguem o propósito formal de transformação dos presos através da educação, do trabalho e da implantação de um regime disciplinar severo e cerceador do contato e interação com o mundo exterior. Todavia, esta tão falada impermeabilidade dessas instituições, que deveria ser modificadora dos indivíduos que nelas ingressam, acaba por prejudicar a preparação desses indivíduos para o retorno à sociedade.

Nesse sentido, Foucault (1979) afirma que tais instituições (as prisões), já desde sua origem, jamais conseguiram se voltar ao projeto de modificação daqueles que nelas ingressam como internados, apenas o modus operandi delas é que se modificou ao longo do tempo. Em "Vigiar e Punir", Foucault (1987) mostra o quanto o saber assume o status de verdade e dá forma à discursividade de uma determinada época. Então, em termos de legislação penal, segundo o autor, cada época criou suas próprias verdades, instituindo e usando os mais variados processos punitivos, que vão do suplício do corpo ao Direito Penal moderno. E complementa: 
[...] desde o começo a prisão devia ser um instrumento tão aperfeiçoado quanto a escola, a caserna ou o hospital, e agir com precisão sobre os indivíduos. $O$ fracasso foi imediato e registrado quase ao mesmo tempo em que o próprio projeto. Desde 1820 se constata que a prisão, longe de transformar os criminosos em gente honesta, serve apenas para fabricar novos criminosos ou para afundá-los ainda mais na criminalidade (FOUCAULT, 1979, p. 131).

Segundo Foucault (1987), desde que na Idade Média foi construída a grande procedura do inquérito, julgar era estabelecer a verdade de um crime, era determinar seu autor, era aplicar-Ihe uma sansão legal. Era, então, apenas necessário conhecer a infração, o responsável e a lei, e, assim, aplicar a pena.

A partir do século XVIII, passa a ser muito mais do que isso: é necessário também perguntar o que significa o crime, o que o motivou. A operação toda deixa de ser puramente uma punição legal, e com isso, o processo todo se torna mais complexo, com um aumento considerável do aparato necessário para julgar um crime. Isso levou a toda uma proliferação de instâncias, atores (peritos, médicos, educadores) e discursos (FOUCAULT, 1987).

Na fase contemporânea, segundo o autor, o discurso pregado não enfatiza tanto o castigo dos delinqüentes, mas a sua recuperação, a fim de integrá-los dóceis e úteis à sociedade. Isso fez com que houvesse uma grande transformação nas estruturas penitenciárias, com intuito de atender às demandas que emergem da sociedade atual. Assim, segundo Foucault (1987), o Direito Penal moderno não ousa mais dizer que pune crimes; ele pretende readaptar os criminosos.

\section{Trajetória Metodológica}

O tipo de pesquisa realizada é exploratória e descritiva, pois o que se pretendeu foi entender e descrever um fenômeno ainda sem muita produção teórica ou conhecimento a respeito. No que concerne à pesquisa exploratória, o objetivo principal residiu na perspectiva de se conhecer melhor a situação ou problema sob o qual a investigação foi direcionada, a fim de se obter dados e idéias que permitissem uma melhor compreensão sobre o assunto estudado (TRIVIÑOS, 1987). No caso em questão, isso se referiu a conhecer as atividades de trabalho remuneradas desenvolvidas na PEM. 
A posição de Triviños (1987) demonstra que quando se fala de estudos descritivos, estes têm por objetivo descrever criteriosamente os fatos e fenômenos de determinada realidade, de forma a obter informações a respeito daquilo que já se definiu como problema e/ou oportunidade a ser investigada. No caso em questão, consistiu em verificar se na concepção dos detentos e do diretor da PEM, as atividades de trabalho remuneradas desenvolvidas pelos detentos são consideradas um instrumento de ressocialização.

A natureza da pesquisa realizada é qualitativa. Pois, para Richardson (1999, p. 90), a pesquisa qualitativa "[...] pode ser caracterizada como tentativa de uma compreensão detalhada dos significados e características situacionais apresentadas pelos entrevistados, em lugar da produção de medidas quantitativas de características ou comportamentos". Este enfoque é bastante flexível, facilitando o processo de pesquisa ao tempo que proporciona uma visão mais abrangente e clara das situações ou organizações que os investigadores estão procurando entender.

O corte temporal desta investigação é transversal, que segundo Richardson (1999, p. 148) este corte temporal ocorre quando "[...] os dados são coletados em um ponto no tempo, com base em uma amostra selecionada para descrever uma população nesse determinado momento".

Os dados utilizados para a investigação foram primários e secundários. Afirma Richardson (1999, p. 253) que “[...] uma fonte secundária é aquela que não tem uma relação direta com o acontecimento registrado, senão através de algum elemento intermediário". Aqui os dados secundários foram coletados por meio dos registros internos da Penitenciária Estadual de Maringá e os externos da Secretaria de Justiça e Departamento Penitenciário do Estado do Paraná.

Os dados primários foram coletados por meio de entrevistas realizadas com os presos e com o diretor da PEM. Para Richardson (1999, p. 253), “[...] uma fonte primária é aquela que teve uma relação física direta com os fatos analisados, existindo um relato ou registro da experiência vivenciada", como é o caso da investigação sistematizada no presente artigo.

Na PEM existiam, na época da coleta de dados, em agosto de 2006, trezentos e sessenta pessoas cumprindo pena e destas, cento e oitenta desenvolvendo atividades de 
trabalho remuneradas em canteiros instalados internamente. $\mathrm{Na}$ PEM existem os canteiros externos (que representam as empresas que utilizam mão-de-obra de presos e os remunera pelo trabalho executado) e os internos (canteiros que também remuneram o trabalho, todavia em forma de pecúlio, pago pelo Estado pelo trabalho do preso). Para a amostra, foram selecionados canteiros de trabalho internos, pela facilidade de acesso. Foram escolhidos, de forma aleatória, dezesseis presos. As entrevistas foram gravadas e transcritas fielmente.

Os dados foram analisados com base na hermenêutica. Para Coreth (1973) o termo hermenêutica, apesar de apresentar uma série de significados (declarar, anunciar, interpretar, esclarecer, entre outros), todos acabam por convergir para a busca de tornar algo compreensível. No nosso caso, esse processo teve por base a interpretação dos autores, levando-se em conta suas vivências, suas visões de mundo, suas reflexões e leituras sobre o tema. Foi um processo de ir e vir, em que perguntar foi uma atividade primordial: perguntar se havia algo velado nas narrativas e o que isso significava; e perguntar para si próprios se o que estavam enxergando das falas transcritas tinha pertinência para o trabalho realizado.

\section{As atividades de trabalho remuneradas desenvolvidas na PEM}

O lócus da pesquisa foi a PEM - Penitenciária Estadual de Maringá, destinada a abrigar presos do sexo masculino em cumprimento de pena privativa de liberdade. A PEM foi inaugurada em 10 de abril de 1996, localizada na área agrícola de Maringá-PR, no limite entre os municípios de Maringá e Paiçandu. Com uma área construída de 5.800 metros quadrados, em um terreno de 24 mil metros quadrados, possui sessenta celas com capacidade para seis presos cada, perfazendo um total de trezentas e sessenta vagas. É dotada de completa infra-estrutura com guaritas, galerias, refeitórios, salas de aula, salas de atendimento, cozinha, panificadora, lavanderia, consultório médico, odontológico e área íntima.

Caracteriza-se como estabelecimento de segurança máxima, destinado a presos do sexo masculino que cumprem pena em regime fechado. Apesar da capacidade de lotação para trezentos e sessenta presos, mantém uma média populacional de trezentos e quarenta e cinco, sendo que destes, $55 \%$ da população carcerária é empregada como 
mão-de-obra em mais de vinte canteiros de trabalho nas áreas de manutenção, artesanato, agricultura, fábrica de bolas de futebol, marcenaria, dentre outros.

Os canteiros de trabalho estão apresentados no Quadro 1. Foram listados separadamente aqueles que são oferecidos pela própria unidade, denominados de canteiros internos, bem como os outros que funcionam mediante convênios entre a Secretaria de Estado da Justiça e da Cidadania e organizações que utilizam mão-de-obra prisional, denominados de canteiros externos. Tais atividades fazem parte dos objetivos institucionais em busca da preparação do preso, em cumprimento de pena, para o seu reingresso na sociedade.

\section{CONVÊNIOS}

01

Antenas Airtrônic Ltda.

02

03

04

05

06

07

08

09

10

01

02

03

Antenas Airtrônic Ltda. Ltda. CAP CAP

Paraná

Barbearia

Biblioteca

Cozinha

\section{CANTEIROS DE TRABALHO EXTERNOS} ATIVIDADES

Montagem de cabos para comunicação, preparo e colocação de terminais nas extremidades de cabos coaxiais.

Montagem de fitas para impressoras. Lixado em jeans. Ferreira \& Scheffer Ltda. Plast Mídia Ind. e Com. Embalagens Plásticas Ltda.

Montagem: colocação de alças,

fundos, ilhó, acabamento e empacotamento de sacolas.

Plast Mídia Ind. e Com. Serviço de serigrafia: revelação de Embalagens Plásticas Ltda.

telas e impressão nas sacolas.

Saiezo Bicicletas do Brasil

Colocação de raios, centragem de aros e montagem completa de bicicletas.

Secretaria Est. de Educação- Digitação de material didático para deficientes visuais.

Secretaria Est. de Educação-

Confecção de mapas e demais desenhos didáticos em alto relevo, bem como maquetes para deficientes visuais.

Universidade Estadual de Restauração de livros da biblioteca da Maringá UEM.

Instituto Ambiental do Produção de mudas.
2006

DATA INÍCIO

2006

2005

1998

1998

2000

2005

2004

2001

2006

1996

1996

1996

\section{CANTEIROS DE TRABALHO INTERNOS}

Corte de cabelo dos presos.

Empréstimo de livros;

catalogação de livros;

relatório de livros emprestados e lidos; faxina nas instalações da biblioteca; restauração dos livros da biblioteca; incentivo à leitura na distribuição de livros nas galerias com acesso limitado. Distribuição da refeição para os presos; limpeza no interior da cozinha; distribuição do café da manhã; serviço de garçom no refeitório dos funcionários (café da manhã, almoço e jantar);

lavagem de louças e utensílios da cozinha; 
preparo de verduras para saladas.

$\begin{array}{ll}06 & \text { Faxina } \\ \mathbf{0 7} & \text { Faxina Externa } \\ \mathbf{0 8} & \text { Horta }\end{array}$

09

Jardinagem
Trabalho de monitoria, auxiliando os professores na alfabetização dos presos.

Limpeza, higienização e recolhimento do lixo no interior da unidade; limpeza das caixas de gorduras; limpeza das viaturas da unidade. Faxina na parte intramuros e reforço no trabalho da horta.

Plantio, colheita e manutenção das instalações da horta; separação de verduras e legumes para uso na unidade e entidade beneficente (Recanto "Somos Todos Irmãos").

Manutenção e plantio de plantas ornamentais.

Controle do fluxo de roupas no setor; lavar e passar as roupas dos presos.

Serviço de consertos da parte elétrica, hidráulica, portões, pintura de paredes, instalação de equipamentos, etc.

Chamar, listar compras e colher assinaturas de presos.

Separação do lixo para reciclagem e reforço na horta.

1998

Quadro 1 - Canteiros de Trabalho / Atividades - 2006

Fonte: Penitenciária Estadual de Maringá/ Divisão Ocupacional - 2006

\section{Percepções dos detentos e do diretor da PEM sobre as atividades de trabalho remuneradas}

Devido à decisão de preservar a identidade dos sujeitos da pesquisa, na discussão que se apresenta a seguir não foram inseridas as falas textuais dos mesmos, mas uma síntese interpretativa de seu conteúdo. 
Há que se destacar, em primeiro lugar, que os presos não escolhem se querem ou não trabalhar, ou ainda, em que canteiros vão trabalhar. Essa decisão é tomada pela organização a partir de determinados critérios, sem a participação direta dos presos.

Em relação à percepção dos presos, o que se notou é que suas falas, em muitos pontos, convergiam entre si. Quando se estabeleceu o diálogo com os presos selecionados, ficou evidente que, no entendimento deles, as atividades de trabalho remuneradas exercidas por eles na PEM são consideradas um instrumento de ressocialização.

Eles acreditam que o fato de exercerem um ofício enquanto estão detidos lhes propicia benefícios, tais como terapia ocupacional, facilidade no convívio com os companheiros, aprendizado e valorização do dinheiro, fruto de seu trabalho. Enfim, melhoria da qualidade de vida.

No entanto, para eles, os benefícios referentes às atividades desenvolvidas na PEM não são apenas imediatos. Acreditam que por meio do trabalho que exercem nos canteiros hoje, é descortinada a perspectiva de que no futuro possam incluir-se socialmente. Afirmam que apesar das limitações em relação às possibilidades de ofícios que possam aprender e/ou exercer na prisão, a probabilidade de alocação no mercado de trabalho, quando forem liberados de suas penas, passa a existir.

Para os detentos, a remuneração recebida referente às atividades de trabalho por eles desenvolvidas auxilia nas vezes em que precisam adquirir produtos de primeira necessidade, como algum alimento, material de higiene, entre outros. Além disso, ajuda suas famílias no período em que estão detidos.

Mais do que isso, o trabalho propicia a eles o preenchimento do tempo vago, tirando-Ihes da ociosidade, contribuindo para o resgate da auto-estima, melhora a imagem que possuem de si mesmos, conseqüentemente, se desenvolvem como seres humanos.

Em termos de limitações do trabalho na prisão, os presos reclamam que existe um controle excessivo do uso e trânsito de ferramentas e em função disso, há perda de uma parcela do tempo, que entendem como prejudicial à produtividade. $\mathrm{O}$ fato dos presos se preocuparem com "produtividade" é interessante nesse contexto, pois eles sabem que 
estão num presídio, e que, portanto, o porte de materiais tem que ser controlado, para que as ferramentas não se transformem, futuramente, em armas em mãos erradas.

Não se pode deixar de comentar que em nenhum dos depoimentos ficou evidenciado o trabalho como parte do cumprimento da pena, ou castigo, e isso nos remete a outro plano de discussão sobre a categoria trabalho, ou seja, como algo estruturante, que sustenta a si e sua família, que ocupa, que profissionaliza, que proporciona crescimento intelectual e que valoriza a pessoa.

Ao se expressarem sobre o trabalho que exercem, os apenados manifestam também suas expectativas sobre como será quando regressarem ao mundo externo e de que forma uma instituição como a PEM poderá contribuir com isso. Eles têm esperança no processo de ressocialização.

Essa também é a percepção do diretor da PEM. Para ele, é possível a ressocialização através do trabalho e, por isso, faz parte da política do sistema prisional da unidade estudada. Para o diretor, as atividades de trabalho exercidas pelos presos podem ser vistas de diversas formas, mas a principal é a ressocialização do preso. É isso que, no seu ponto de vista, auxilia que a PEM atinja o seu objetivo e justifique a sua existência.

Lembra ele que segundo a Lei de Execução Penal, a finalidade social é proporcionar aos apenados as condições mínimas (os meios) para que se configure uma perspectiva futura de reintegração social para essas pessoas, cuja condição de segregação necessita de atenção especial, com o intuito de minimizar a possibilidade da reincidência criminal.

Acrescenta ainda que o trabalho faz com que os presos aprendam a cumprir horário, obedecer às normas prescritas, ou seja, a se disciplinarem, o que facilita o trabalho dos técnicos administrativos, para que estes possam auxiliá-los, no sentido de resolver problemas de ordem física e psicológica.

Comenta que o processo de aprendizagem profissional, na maioria dos casos, redireciona os objetivos do preso, o que faz acender a esperança de que ele seja mais um ser humano digno de voltar ao convívio social, sem oferecer risco à sociedade. Segundo o diretor, há casos de presos que foram liberados de suas penas e empreenderam seus próprios negócios; outros que estão desenvolvendo as atividades que aprenderam na prisão em empresas que possuem convênios com a PEM. No entanto, ressalta o diretor, 
não se pode generalizar, pois há sempre aqueles que têm dificuldades de se adaptarem novamente à sociedade.

É aí que se localiza sua preocupação maior: a angústia que caracteriza o preso próximo a sair em liberdade, pois como dissemos anteriormente, nesse momento se configura a esperança que representa uma instituição total: a reabilitação.

Por fim, acrescenta o diretor que o sistema penitenciário paranaense vem envidando esforços em busca da viabilização de trabalho para o preso, bem como a educação formal e profissionalizante, a prática de esporte, o lazer e, na medida do possível, o contato com o que acontece no mundo exterior. Ressalta que na PEM estas e outras atividades encontram-se implantadas e que elas fazem parte de um conjunto de instrumentos que visa a ressocialização dos presos.

\section{Conclusões}

Da pesquisa empreendida, concluí-se que as atividades de trabalho remuneradas desenvolvidas pelos detentos na PEM estão de acordo com os objetivos prescritos no art. 28 da LEP, ou seja, pela Lei no. 7.210 de 11/07/1984. Apesar de a PEM ser uma instituição total, e portanto, ter certo grau de fechamento em relação à sociedade, alguma abertura foi necessária para que ela pudesse instalar canteiros de trabalho como atividade rotineira e assim conseguir cumprir o que prescreve a lei.

Os dados primários e secundários mostram que diversos tipos de atividades de trabalho remuneradas são desenvolvidos na PEM. Estas atividades possuem características simples, que não demandam mão-de-obra com alta qualificação, nem tampouco grau de instrução elevado. Apesar da "singeleza" das atividades, no entanto, elas têm o poder de aumentar a auto-estima dos que estão internados. Isso pôde ser observado durante as entrevistas, pela expressão facial e pelo entusiasmo com que os detentos falavam de seus trabalhos, levando-nos à conclusão de que, para eles, o trabalho que desenvolviam era algo estruturante em suas vidas.

Interpretando as colocações feitas no decorrer do trabalho de campo, vimos que tanto por parte do diretor como dos presos entrevistados, há uma reprodução dos discursos oficiais quanto à necessidade do trabalho prisional e da sua importância para a 
ressocialização. Isso aliena mais ainda os detentos. Tomando por base Etzioni (1974), notamos que essa alienação é congruente com o modelo de organização em que estão inseridos e também com os discursos atuais sobre ele. A decisão sobre o tipo de trabalho a ser desenvolvido parte da organização, assim como a decisão de quem irá trabalhar. Por isso, o preso permanece alienado - nos termos de Etzioni (1974) - uma vez que não participa, enquanto sujeito, do processo de decisão em relação à função que desenvolve. Apenas aceita os discursos, as imposições e as coerções do tipo de organização em que está inserido.

Assim, mesmo que os padrões coercitivos utilizados na manutenção do controle de tais instituições variem substancialmente, a coerção não deixa de existir. Se na atualidade, esses padrões coercitivos não podem fugir dos parâmetros estabelecidos e normatizados para os tipos de punição que devem ser aplicados para determinados tipos de faltas, é porque eles estão em sintonia com os discursos atuais. Ou seja, "formalmente" não se fala mais em suplício do corpo; como diria Foucault (1987), o Direito Penal moderno pretende readaptar os criminosos.

A interpretação das narrativas mostra exatamente a reprodução desse discurso, tornando mais claro o quanto a lógica de funcionamento das instituições totais inibe, ou até mesmo extingue a autonomia e o espírito crítico dos indivíduos, com o intuito de torná-los, nas palavras de Goffman (1974), inertes, obedientes e submissos. Ou, nas palavras de Foucault (1987), dóceis e úteis à sociedade.

Assim, se para Foucault (1987) cada época criou suas próprias verdades, instituindo e usando os mais variados processos - no caso das instituições totais, processos punitivos - o que se pode notar, a partir da pesquisa empreendida, é que o modus operandi da PEM está em sintonia com o que a sociedade idealizou para esse tipo de instituição na atualidade: ao mesmo tempo em que existe o exercício do controle e da dominação, há também um discurso que tem como proposta a possibilidade de ressocialização do preso.

Por isso é que podemos chegar à conclusão de que a PEM é uma instituição útil à sociedade atual. Ou seja, nas palavras de Goffman (1974), ela é um tipo de instituição total que protege a comunidade contra perigos intencionais, isola essas pessoas perigosas e, estando assim isoladas, elas não constituem um problema imediato para a sociedade. Além disso, as atividades de trabalho ali desenvolvidas coadunam com o discurso de que 
a reinserção dos presos à sociedade venha a ocorrer concomitantemente com maiores condições de ressocialização.

Como pesquisa exploratória, esta investigação foi apenas um primeiro passo para novas conclusões. Para isso, em termos de futuras pesquisas, sugerimos investigar a "trajetória" de ex-apenados que trabalharam nos canteiros da PEM, no intuito de constatar se realmente houve um processo de ressocialização e inserção no mundo do trabalho. Além disso, seria interessante fazer estudos comparativos entre diversas penitenciárias, que utilizam ou não do trabalho prisional, e fazer análises quantitativas em termos de reincidências no crime, índices de ressocialização, entre outros indicadores, que poderiam ser úteis nas reflexões sobre este tipo de instituições totais.

\section{Referências}

BLAU, P. M.; SCOTT, W. R. Organizações formais. São Paulo: Atlas, 1977.

BRASIL. Presidência da Republica. Lei no 7.210, de 11 de julho de 1984. Institui a Lei de Execução Penal. Disponível em: <http://www.planalto.gov.br/ccivil_03/Leis/L7210.htm>. Acesso em: 12 nov. 2010.

CORETH, E. Questões fundamentais de hermenêutica. São Paulo: EPU, 1973.

ETZIONI, A. Análise comparativa de organizações complexas. São Paulo: Universidade de São Paulo, 1974.

FOUCAULT, M. Microfísica do poder. Rio de Janeiro: Graal, 1979.

. Vigiar e punir. Petrópolis: Vozes, 1987.

GOFFMAN, E. Manicômios, prisões e conventos. São Paulo: Perspectiva, 1974.

HALL, R. Organizações: estrutura e processo. Rio de Janeiro: Prentice Hall, 2004.

PARANÁ. Secretaria de Estado da Justiça e da Cidadania - SEJU. Departamento penitenciário do estado: relatório. Curitiba, 2005.

PERROW, C. Análise organizacional: um enfoque sociológico. São Paulo: Atlas, 1972.

RICHARDSON, R. J. Pesquisa social: métodos e técnicas. São Paulo: Atlas, 1999.

SILVA, R. O que as empresas podem fazer pela reabilitação do preso. São Paulo: Instituto Ethos, 2001.

SROUR, R. H. Poder, cultura e ética nas organizações. São Paulo: Campus, 1998. 
TRIVIÑOS, A. N. S. Introdução à pesquisa em ciências sociais: a pesquisa qualitativa em educação. São Paulo: Atlas, 1987. 